\title{
The effects of ZD1839 (Iressa), a highly selective EGFR tyrosine kinase inhibitor, as a radiosensitiser in bile duct carcinoma cell lines
}

\author{
HIDEKI MIYATA, TAMITO SASAKI, KENICHI KUWAHARA, \\ MASAHIRO SERIKAWA and KAZUAKI CHAYAMA
}

\begin{abstract}
Department of Medicine and Molecular Science, Division of Frontier Medical Science, Programs for Biochemical Research, Graduate School of Biomedical Sciences, Hiroshima University, 1-2-3 Kasumi, Minami-ku, Hiroshima 734-8551, Japan
\end{abstract}

Received October 5, 2005; Accepted November 29, 2005

\begin{abstract}
The signaling pathway that is initiated by binding of epidermal growth factor receptor (EGFR) and results in sustained signaling through PI3K plays an important role in a tumor's response to ionizing radiation. The current in vitro study explored both the effects of ZD1839 (Iressa), a highly selective EGFR tyrosine kinase inhibitor, as a radiosensitiser for bile duct carcinoma cell lines and ZD1839's general effects on cell growth in the same two lines. Secondly, we ensured suppression of radiation-induced phosphorylation of EGFR by ZD1839 using an immunoprecipitation technique. Furthermore, we examined radiation-induced phosphorylation of ERK, p38, JNK, and AKT with or without inhibitor with use of Western blot techniques and performed clonogenic assays to confirm radiosensitivity in the presence of a drug. ZD1839 inhibited cell growth of both cell lines and suppressed radiation-induced phosphorylation of EGFR. After exposure to radiation, there was an increase in phosphorylation of AKT as shown by Western blot. Treatment with either ZD1839 or LY294002 (the latter, a PI3K inhibitor) suppressed phosphorylation of AKT by Western blot. Both ZD1839 and LY294002 significantly suppressed colony formation by clonogenic assay; however, U0126 (a MEK1/2 inhibitor), SB203580 (a p38 inhibitor), and SP600125 (a JNK inhibitor) had no effect on colony formation. These results suggest that AKT may be a useful target molecule for enhancement of radiotherapy effect and that ZD1839 may have an important role in combination with radiotherapy for patients with bile duct carcinoma.
\end{abstract}

Correspondence to: Dr Hideki Miyata, Department of Medicine and Molecular Science, Division of Frontier Medical Science, Programs for Biochemical Research, Graduate School of Biomedical Sciences, Hiroshima University, 1-2-3 Kasumi, Minami-ku, Hiroshima 7348551, Japan

E-mail: hideki00@hiroshima-u.ac.jp

Key words: ZD1839, EGFR, AKT, radiation, bile duct carcinoma

\section{Introduction}

Bile duct carcinoma (BDC) is a malignancy with a poor prognosis. Complete surgical resection is the only hope for long-term survival, but only a small fraction of patients are candidates for curative surgery. For patients with unresectable disease, management of obstructive jaundice associated with BDC is necessary. Use of an expanding metallic stent (EMS) has been applied as treatment of obstructive jaundice. In the effort to extend stent patency and patient survival, clinicians have employed radiation therapy using a remote afterloading system (RALS); reports indicate that durations of stent patency and patient survival after RALS radiotherapy are significantly longer than those associated with EMS treatment only (1-3). However, because most BDCs are histologically adenocarcinoma and are considered radioresistant cancers, further improvements in outcome require development of effective radiosensitisers.

The epidermal growth factor receptor (EGFR) family consists of four closely related growth factor receptors, including EGFR, erbB-2, erbB-3, and erbB-4. Amplification of EGFR and erbB-2 occurs in a subset of human tumors including cancers of the breast, lung, and ovary (4). EGFR is expressed or overexpressed in a wide variety of solid human tumors, including non-small cell lung (NSCL) cancer, as well as cancer of the prostate, breast, stomach, colon and rectum, head and neck, bladder, and ovary (5). Activation of EGFR initiates the cascade of intracellular signaling events that leads to proliferation, cell survival, angiogenesis, and metastasis. EGFR expression has been observed in about $44.7 \%$ of cases of BDC and is considered to be a contributor to disease progression (6). Overexpression of erbB-2 in breast and ovarian cancer is associated with particularly aggressive clinical behavior and poor prognosis (7). In BDC, the frequency of overexpression of erbB-2 has been reported in the range from 26.3 to $52.6 \%(6,8-10)$.

Activation of EGFR initiates signaling through two main downstream pathways, the Ras/Raf/MAPK pathway and the $\mathrm{PI}$ KK/AKT pathway. The Ras to MAPK pathway is perhaps the most extensively studied, and it consists of at least three sequential kinase cascades that include the Ras/Raf/MAPK (also known as ERK) pathway, the stress-activated SAPK/JNK 
pathway, and the p38 pathway. These signals play critical roles in controlling cell survival, and they are activated in response to multiple cellular stresses including tumor necrosis factor, osmotic stress, and heat shock $(11,12)$. Activation of these pathways after irradiation has been reported in several carcinoma cell lines (13-15). In contrast, other research groups have reported that activation of MAPK, JNK, and p38 are not involved in resistance to radiation (16-18). The activation status of these pathways in BDC has not been reported to date.

The PI3K-AKT pathway is known to be anti-apoptotic in nature, with positive effects on cell survival, cell cycle progression and motility (19-21). Recently, some reports have suggested that the PI3K-AKT pathway contributes to radioresistance (22-24). A relationship between radioresistance and the PI3K-AKT pathway has also been reported with BDC cell lines (25).

The tyrosine kinase inhibitor ZD1839 (Iressa) is a synthetic anilinoquinazoline tyrosine kinase inhibitor that is selective for EGFR. Specifically, ZD1839 selectively inhibits the tyrosine kinase activity of EGFR and erbB-2 with a $50 \%$ inhibitory concentration $\left(\mathrm{IC}_{50}\right)$ of 0.02 and $2 \mu \mathrm{M}$, respectively (26; Woodburn JR, et al, Proc Am Assoc Cancer Res 37: 390391, 1996). In many cancer cell lines that overexpress EGFR and erbB-2, particularly, breast cancer cell lines, ZD1839 completely abolishes autophosphorylation of EGFR with resulting inhibition of activation of downstream signaling molecules. Positive effects of ZD1839 in combination with radiotherapy have been reported with bladder cancer (27), head and neck cancer (28), glioblastoma (29), colorectal cancer (30), squamous cell carcinoma $(31,32)$, and breast cancer $(33)$. However, combination therapy with ZD1839 and radiotherapy in BDC has not yet been reported.

In the present study, we examined the relationships in BDC cell lines among radiation response and key molecules such as the signaling pathways initiated by binding of EGFR. Furthermore, by blocking molecules or signals with ZD1839, we explored whether ZD1839 is a potentially useful agent for therapy in combination with radiation for patients with BDC.

\section{Materials and methods}

Reagents. The PI3K inhibitor LY294002 and the p38 inhibitor SB203580 were obtained from Sigma Aldrich Company (Tokyo, Japan). The MEK1/2 inhibitor U0126 was obtained from Cell Signaling (Beverly, MA, USA). The JNK inhibitor SP600125 was obtained from Calbiochem (San Diego, CA, USA). ZD1839 was provided as a kind gift by AstraZeneca Pharmaceuticals (Macclesfield, UK). All inhibitors were resuspended in dimethyl sulfoxide (DMSO) to give a $10-\mathrm{mM}$ stock solution and further diluted with medium immediately prior to use in experiments.

Mouse anti-phosphotyrosine (PY99) antibody, rabbit polyclonal anti-EGFR antibody, rabbit polyclonal anti-erbB-2 antibody, and rabbit polyclonal anti-erbB-3 antibody were obtained from Santa Cruz Biotechnology (Santa Cruz, CA, USA). Nine reagents, phospho-AKT (Ser473) antibody, AKT antibody, phospho-SAPK/JNK (Thr183/Tyr185) antibody, JNK antibody, phospho-p38 (Thr180/Tyr182) antibody, p38 antibody, phospho-p44/42 MAPK (Thr202/Tyr204) antibody, ERK anti- body, and HRP-conjugated anti-rabbit antibody, were obtained from Cell Signaling.

Cells. HuCCT-1, a human cholangiocellular carcinoma cell line, and TFK-1, a BDC cell line, were obtained from the Institute of Development, Aging and Cancer, Tohoku University. Cells were cultured in RPMI-medium supplemented with $10 \%$ fetal bovine serum (FBS), penicillin (100 units/ml), and streptomycin $(100 \mathrm{mg} / \mathrm{ml})$ at $37^{\circ} \mathrm{C}$ in humidified $5 \% \mathrm{CO}_{2^{-}}$ $95 \%$ air.

Proliferation assay. HuCCT-1 and TFK-1 cells were treated with various concentrations $(0-10 \mu \mathrm{M})$ of ZD1839 for $48 \mathrm{~h}$ in RPMI supplemented with $0.1 \%$ FBS before cell proliferation assays were carried out using the BrdU system (enzyme-linked immunosorbent assay, ELISA; Amersham Pharmacia Biotech) according to the manufacturer's protocol. The absorbance at $450 \mathrm{~nm}$ of aliquots of cell supernatants was measured using an automatic plate analyzer (Pharmacia, Tokyo, Japan). Each experiment was performed twice, both times in triplicate.

Clonogenic assay. Cultured cells in log growth phase were counted, and 1000 cells were seeded on 10-cm Petri dishes containing $10 \mathrm{ml}$ medium treated with test agents or vehicle (DMSO). Each agent was added at least $1 \mathrm{~h}$ before irradiation, and $24 \mathrm{~h}$ after irradiation the cells were transferred to drugfree medium. Irradiation sessions were performed with serial doses of 1,3 , and 5 Gy with a ${ }^{60}$ Co irradiator (Shimadzu, Japan) at a dose rate of $0.7 \mathrm{~Gy} / \mathrm{min}$. Cells were incubated for 14-21 days. Colonies were fixed with $4 \%$ paraformaldehyde and stained with crystal violet (viable dye) before being counted. Each colony was assessed individually using Kodak Digital Image Analyzer ${ }^{\mathrm{TM}}$ version 3 (Eastman Kodak Co.) to ascertain the presence of a diameter of at least $150 \mu \mathrm{m}$. Cell survival fraction was calculated as previously reported (34): number of colonies formed/(number of cells seeded x plating efficiency/ 100). Each point on the survival curve represents the meansurviving fraction from at least three dishes.

Western blot analysis and immunoprecipitation analysis. Cells from both lines were plated until they reached subconfluence, and then they were starved in serum-free medium for $24 \mathrm{~h}$. The resulting monolayers were then exposed to ZD1839 for $1 \mathrm{~h}$ or exposed to other inhibitors at least $1 \mathrm{~h}$ before irradiation. Cells were irradiated with use of a ${ }^{60} \mathrm{Co}$ irradiator ( $3 \mathrm{~Gy}$ ) and medium was removed at defined times (5 or $15 \mathrm{~min}$ ) before cells were washed twice with ice-cold phosphate buffered saline (PBS) and lysed with RIPA buffer [0.05 M Tris- $\mathrm{HCl}$ (pH 7.4), $0.15 \mathrm{M} \mathrm{NaCl}, 0.25 \%$ deoxycholic acid, $1 \%$ NP-40, 1 mM EDTA], phosphatase inhibitor (1 mM PMSF, $1 \mathrm{mM}$ sodium orthovanadate, $1 \mathrm{mM}$ sodium fluoride), and protease inhibitor $(1 \mu \mathrm{g} / \mathrm{ml}$ aprotinin, $1 \mu \mathrm{g} / \mathrm{ml}$ leupeptin, $1 \mu \mathrm{g} / \mathrm{ml}$ pepstatin). The samples were incubated at $4^{\circ} \mathrm{C}$ for $30 \mathrm{~min}$ and then scraped. After sonication and removal of cell debris by centrifugation, protein concentration was determined by bovine serum albumin (BSA) protein assay reagent kit (Pierce, France) per manufacturer's instructions. The samples were boiled for $5 \mathrm{~min}$ at $95^{\circ} \mathrm{C}$ and stored at $-20^{\circ} \mathrm{C}$. For immunoprecipitation, lysate samples containing equal amounts of protein were incubated with rabbit polyclonal anti-EGFR 
antibody overnight at $4^{\circ} \mathrm{C}$ with slow agitation. The next day, $50 \mu \mathrm{g}$ protein $\mathrm{G}$-Sepharose was added for $2 \mathrm{~h}$ at $4^{\circ} \mathrm{C}$, and then the immunocomplexes were pelleted by centrifugation and washed twice with immunoprecipitation lysis buffer. Samples containing equal amounts of protein were diluted three times with Laemmli sample buffer and separated on 7 or $10 \%$ sodium dodecyl sulphate (SDS) polyacrylamide gels and transferred to nitrocellulose membranes. Membranes were blocked in (TBST) containing 5\% non-fat milk for $1 \mathrm{~h}$ at room temperature and exposed to primary antibody overnight at $4^{\circ} \mathrm{C}$. Secondary antibodies were added for $1 \mathrm{~h}$ at room temperature. Blots were developed with enhanced chemiluminescence (Perkin-Elmer, Boston, MA, USA) and exposed to Kodak X-Omat Blue film.

Statistical analysis. Statistical analysis was performed with Scheffe's F test. Results are presented as the average \pm standard deviation (SD) of triplicate samples from at least two independent experiments. A p-value $<0.05$ was considered to be statistically significant. The analysis was performed with Statistica software (StatSoft, USA).

\section{Results}

Cell proliferation assay. At first, we investigated the effects of ZD1839 on growth of HuCCT-1 and TFK-1 cell lines using the BrdU ELISA system. Both lines of cells expressed EGFR, erbB-2, and erbB-3 protein (Fig. 1a). HuCCT-1 was found to be homozygous for mutated K-Ras by Auto sequence, whereas TFK-1 had wild-type K-Ras (data not shown). Cell proliferation values are expressed as a percentage of the proliferation of cells cultured in the absence of ZD1839. ZD1839 inhibited proliferation of both cells in a dose-dependent manner (Fig. 1b). ZD1839 (10 $\mu \mathrm{M})$ significantly inhibited cell growth compared with control HuCCT-1 cells $(\mathrm{p}=0.001)$ and control TFK-1 cells $(\mathrm{p}=0.005)$. The $50 \%\left(\mathrm{ED}_{50}\right)$ of $\mathrm{ZD} 1839$ for the HuCCT-1 and TFK-1 lines were 1.158 and $2.658 \mu \mathrm{M}$, respectively.

Inhibition of radiation-induced phosphorylation of EGFR by ZD1839. When we examined the effect of ZD1839 on radiation-induced phosphorylation of EGFR in the HuCCT-1 and TFK-1 cell lines, we found EGFR in both lines were not phosphorylated before irradiation, but EGFR in both cell lines were significantly phosphorylated at 5 min after irradiation. A $1-\mu \mathrm{M}$ concentration of ZD1839 inhibited radiation-induced autophosphorylation of EGFR in both cell lines (Fig. 2).

$A K T, M A P K, J N K$, and $p 38$ activation in response to radiation. To ensure activation of AKT, MAPK, p38, and JNK in response to radiation, we examined phosphorylation of these proteins at different time intervals after radiation by Western blot analysis. Levels of phosphorylated protein were uniformly elevated after irradiation: phospho-ERK, phospho-p38, and phospho-JNK levels reached their peaks at 15 min after irradiation and returned to almost baseline levels at $2 \mathrm{~h}$. The phosphorylation level of AKT also reached its peak at $15 \mathrm{~min}$ after irradiation, returning to almost baseline levels at $2 \mathrm{~h}$ (Fig. 3).

Inhibition of the downstream pathway of EGFR. To examine whether ZD1839 inhibited radiation-induced up-regulation of a

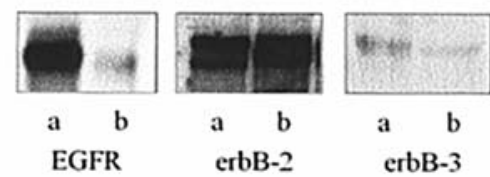

b

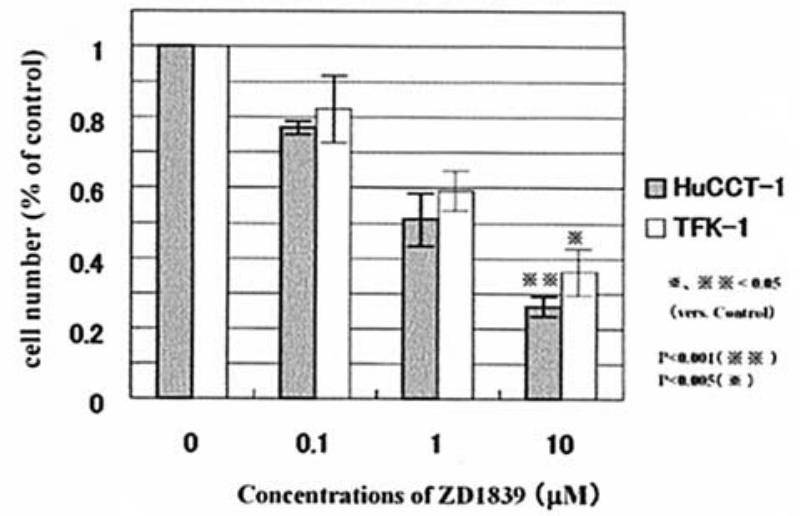

Figure 1. ZD1839-induced effects on growth of BDC cells. (a), Both cell lines were plated until subconfluence and then starved in serum-free medium for $24 \mathrm{~h}$. Whole cell lysates were subjected to $7 \%$ sodium dodecylsulphate polyacrylamide gel electrophoresis (SDS-PAGE) and Western blotting using anti-EGFR antibody, anti-erbB-2 antibody, or anti-erbB-3 antibody. EGFR, erbB-2, and erbB-3 protein were expressed in both cell lines (a, HuCCT-1 and $b, T F K-1)$. (b), Both lines were exposed to different concentrations of ZD1839. After $72 \mathrm{~h}$ of exposure, both cell lines were evaluated using the BrdU system as described in Materials and methods. ZD1839 significantly inhibited proliferation of HuCCT-1 $(\mathrm{p}=0.001)$ and TFK-1 $(\mathrm{p}=0.005)$ cells in a dose-dependent manner. Cell proliferation was expressed as a percentage of the proliferation of cells cultured in the absence of ZD1839. Data represent the mean \pm SD of triplicate samples from at least two independent experiments. Asterisks indicate significant differences (Scheffe's F test, ${ }^{*} \mathrm{p}<0.05$ ).

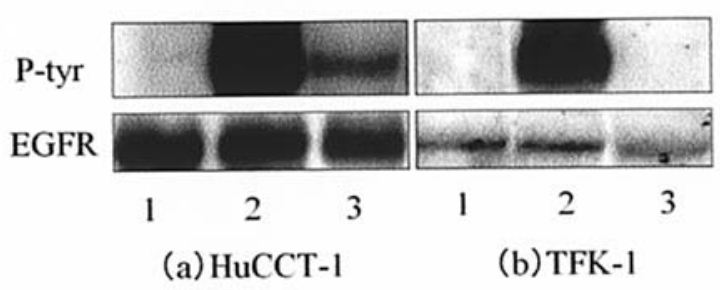

Figure 2. Inhibition of radiation-induced phosphorylation of EGFR by ZD1839. Both BDC cell lines were treated with or without $1 \mu \mathrm{M}$ ZD1839 for $1 \mathrm{~h}$, then immunoprecipitated with anti-EGFR antibody $5 \mathrm{~min}$ after irradiation, electrophoresed, and blotted with antiphosphotyrosine antibody (P-tyr) or anti-EGFR. ZD1839 inhibited radiation-induced phosphorylation of EGFR in both cell lines [(a), HuCCT-1 and (b), TFK-1]. Lane 1, control (nontreated); lane 2, irradiation (3 Gy); lane 3, irradiation (3 Gy) and ZD1839.

the downstream pathway of EGFR, we performed Western blotting for phospho-ERK, phospho-p38, phospho-JNK, and phospho-AKT. Inhibitors were added to culture at least $1 \mathrm{~h}$ prior to radiation. Proteins for ERK, p38, JNK, and AKT analysis were extracted $15 \mathrm{~min}$ after radiation. The inhibitors U0126 $(20 \mu \mathrm{M}), \mathrm{SB} 203580(20 \mu \mathrm{M})$, and SP600125 $(20 \mu \mathrm{M})$ suppressed radiation-induced phosphorylation of ERK, p38, and JNK in both cell lines. The inhibitor LY294002 (10 $\mu \mathrm{M})$ 


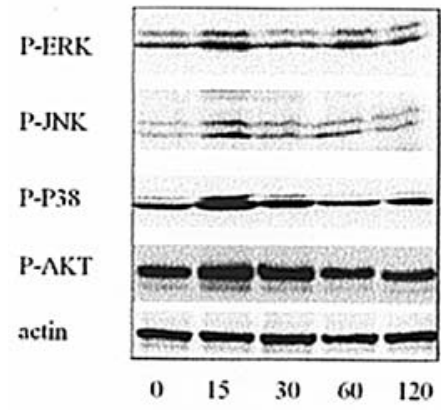

(a) $\mathrm{HuCCT}-1$

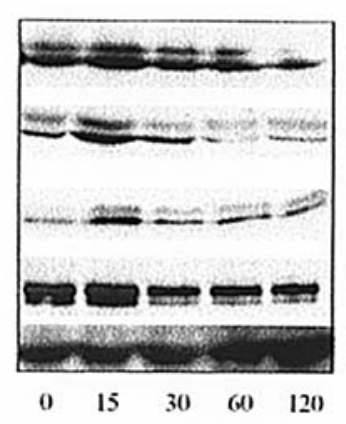

(b) TFK-1
Figure 3. Radiation-induced phosphorylation of ERK, p38, JNK, and AKT. Both BDC cell lines were pretreated as described in Materials and methods. Whole cell lysates were prepared and used for Western blot analysis. At $15 \mathrm{~min}$ after irradiation, phosphorylated-ERK, p38, JNK, and AKT levels were elevated; levels returned to near baseline levels after $2 \mathrm{~h}$ in both cell lines [(a), HuCCT-1 and (b), TFK-1].

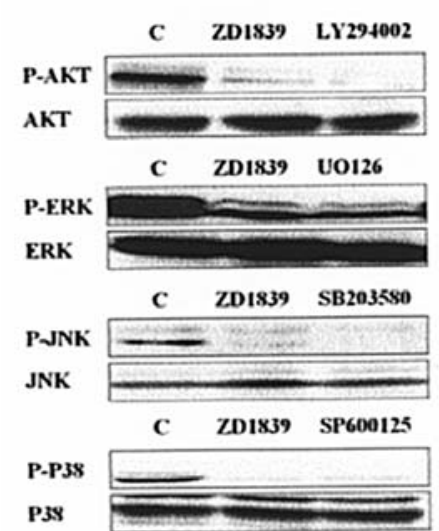

(a) HuCCT-1

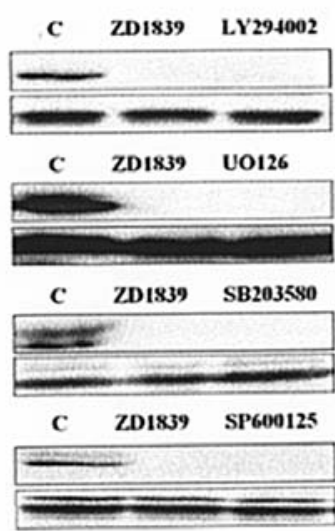

(b)TFK-1
Figure 4. Effects of ZD1839 and other inhibitors on radiation-induced downstream signaling pathways of EGFR. U0126 $(20 \mu \mathrm{M}), \operatorname{SB} 203580(20 \mu \mathrm{M})$, and SP600125 $(20 \mu \mathrm{M})$ suppressed radiation-induced phosphorylation of ERK, p38, and JNK, respectively, in both cell lines. LY294002 $(10 \mu \mathrm{M})$ also suppressed radiation-induced phosphorylation of AKT in both cell lines. ZD1839 $(1 \mu \mathrm{M})$ suppressed all radiation-induced phosphorylation of ERK, p38, JNK, and AKT in both cell lines [(a), HuCCT-1 and (b), TFK-1].

also suppressed radiation-induced phosphorylation of AKT in both cell lines. A $1-\mu \mathrm{M}$ concentration of ZD1839 inhibited the radiation-induced phosphorylation of ERK, p38, JNK, and AKT in both cell lines (Fig. 4). These results revealed that ZD1839 inhibited radiation-induced phosphorylation of EGFR and the downstream pathway.

Clonogenic assay and radiosensitivity. Clonogenic cell survival times of both cell lines were decreased by radiation in a dosedependent manner. Pretreatment with either ZD1839 or LY294002 enhanced the radiation-related suppression of clonogenic cell survival. The survival fraction ratios of HuCCT-1 cells under 3 Gy-irradiation were 0.7 (control), 0.51 (ZD1839), and 0.35 (LY294002) compared with survival of untreated cells (Fig. 5a). Ratios of TFK-1 cells were 0.6 (control), 0.37 (ZD1839) and 0.36 (LY294002), respectively (Fig. 5b). Moreover, these effects with both cell lines were obvious under
5 Gy-irradiation. These results indicated that pretreatment with ZD1839 or LY294002 potentiated the radiosensitivity of BDC. Subsequently, to ensure that the downstream signaling pathway of EGFR contributed to the observed radiosensitivity, we employed clonogenic assays using blocking agents such as U0126 for MEK1, SB203580 for p38, and SP600125 for JNK. Survival fraction ratios for both cell lines after use of blocking agents were similar to those obtained with irradiation alone (Fig. 5c and d). Under conditions of non-irradiation, inhibitors did not affect clonogenic cell survival values for either cell line (data not shown). These results suggested that none of the signaling pathway involving MEK-ERK, p38, or JNK contributed to the observed radiosensitivity of BDC.

\section{Discussion}

Because BDC is generally characterized as a cancer with a relatively low frequency of distal metastasis, curative surgical resection potentially improves patient survival. Hepatic lobectomy or pancreatoduodenectomy are often necessary for curative resection. However, the stress associated with those surgical procedures is extremely high, so clinicians find a number of patients are not good surgical candidates due to the patient's general condition. In those cases, radiation therapy is considered a useful therapeutic strategy for patient survival in addition to prolongation of stent patency, with stents implanted to relieve biliary obstruction. However, the response to radiation of BDC is generally worse than those for other malignancies such as head and neck cancer or cervical cancer. Radiation-induced signal transduction and the regulatory mechanism of radioresistance in BDC have not been well investigated. Thus, in the present study, we initially investigated radiation-induced activation of signaling molecules in BDC.

Some reports indicate that the level of EGFR is correlated with degree of radioresistance $(35,36)$. Ionizing radiation activates autophosphorylation of EGFR and increases the activity of protein tyrosine kinase without ligand binding to receptor. The autophosphorylation of EGFR induces activation of downstream pathways. In the current study, immunoprecipitation assay and Western blotting using phosphospecific antibody demonstrated that irradiation stimulates phosphorylated signals for ERK, JNK, p38, and AKT, as well as autophosphorylation of EGFR. Protein phosphorylation was suppressed by pretreatment with each inhibitor (Figs. 3 and 4). These results with BDC cell lines are consistent with previous research conducted with other kinds of cancer.

Because it has been suggested that various signaling pathways are stimulated by ionizing radiation, we subsequently investigated the relationships between radiosensitivity and these signaling molecules. Clonogenic assays demonstrated that the inhibitor LY294002 suppressed radiation-induced clonogenic cell survival (Fig. 5a and b); in contrast, U0126 $(20 \mu \mathrm{M}), \mathrm{SB} 203580(20 \mu \mathrm{M})$, and SP600125 $(20 \mu \mathrm{M}) \mathrm{did}$ not alter cell survival (Fig. $5 \mathrm{c}$ and d). These results suggest that radiation-induced phosphorylated signals through ERK, p38, and JNK are not involved in radioresistance of BDC, whereas the PI3K-AKT pathway appears to play an important role in its radioresistance.

EGFR can signal directly to PI3K or indirectly through Ras to PI3K. Ras signals to PI3K by binding and activating its 
a
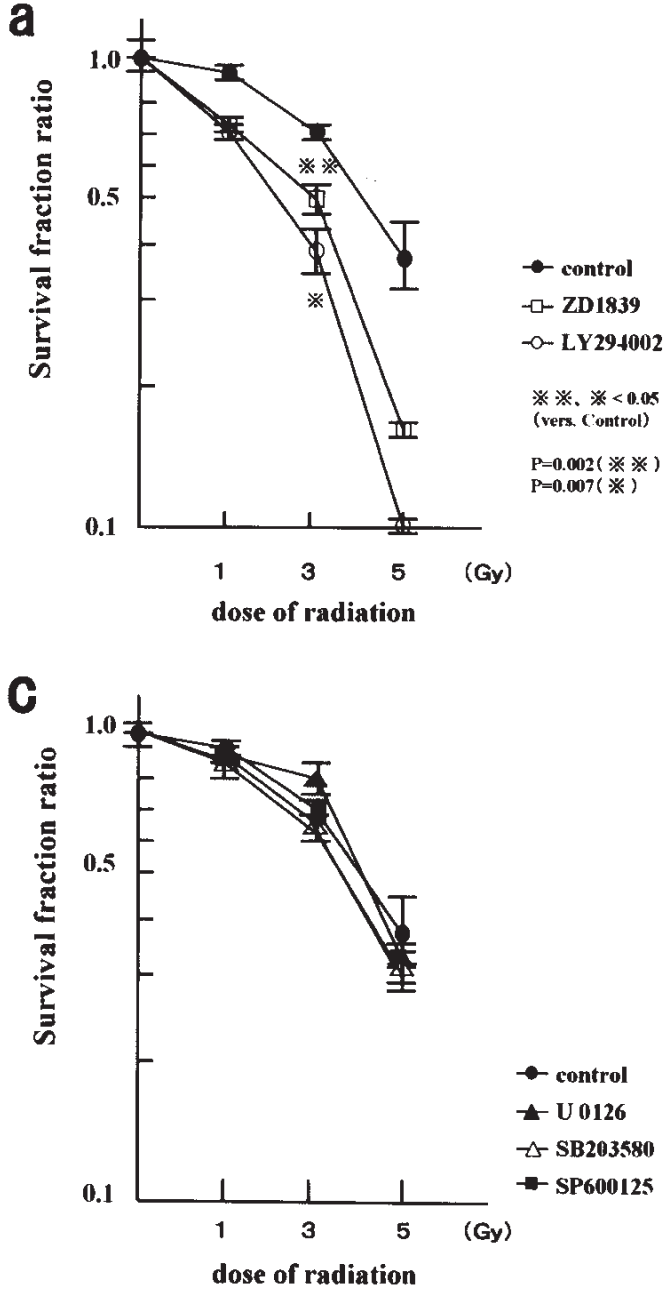

b

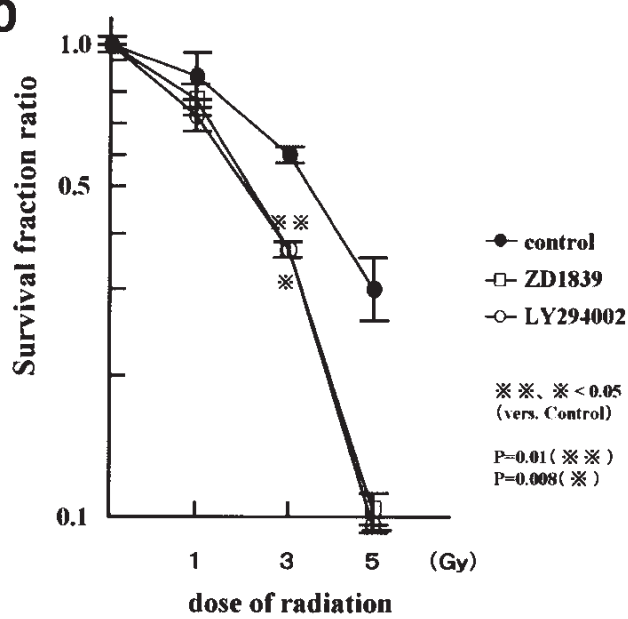

d

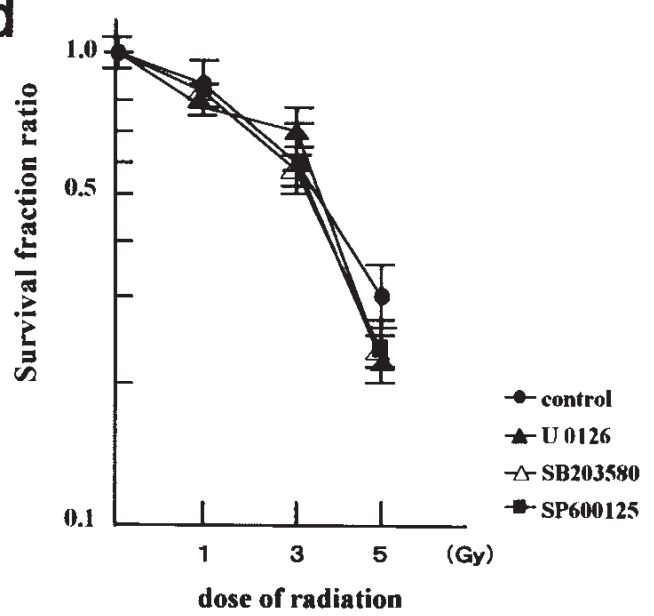

Figure 5. Radiosensitising effect of ZD1839 and other inhibitors. Radiation survival curves were plotted for different radiation doses (1, 3, 5 Gy) and with or without pretreatment with inhibitors [HuCCT-1 (a and c), TFK-1 (b and d)]. A highly significant radiosensitising effect was seen for both cell lines compared with control cells (closed circle) when treated with ZD1839 (open square) or LY294002 (open circle). However, significant effects were not demonstrated for either cell line when treated with U0126 (20 $\mu \mathrm{M})$ (closed triangle), SB203580 (20 $\mu \mathrm{M})$ (open triangle), or SP600125 (20 $\mu \mathrm{M})$ (closed square). Survival fraction is expressed as a percentage of the proliferation of cells cultured in non-treatment conditions (neither irradiation nor inhibitors). Data shown represent the mean $\pm \mathrm{SD}$ of triplicate samples from at least two independent experiments. Asterisks indicate significant differences $\left(\right.$ Scheffe's $\mathrm{F}$ test, $\left.{ }^{*} \mathrm{p}<0.05\right)$.

p110 unit. PI3K phosphorylates phosphatidylinositol (PtdIns) phosphates, leading to conversion of PtdIns 4,5-p2 to PtdIns 3,4,5-p3. This lipid second messenger activates phosphositidedependent kinases (PDK), which then activate AKT. By stimulation with growth factor and cytokines, AKT is phosphorylated at two key regulatory sites, Thr308 in the activation loop of the catalytic domain and Ser473 in the COOH-terminal regulatory domain (37). Phosphorylation of AKT at Thr308 and Ser473 is catalyzed by PDK1 (38) and by an unknown protein kinase, respectively. Activated AKT phosphorylates the pro-apoptotic factor, Bcl-2 family member Bad, caspase family member caspase-9, Forkhead family transcription factor FKHRL1, and IкB kinases $(39,40)$.

AKT has been implicated as an anti-apoptotic factor in many different cell death paradigms, including the withdrawal of extracellular signaling factors, oxidative and osmotic stress, irradiation, and treatment of cells with chemotherapeutic drugs and ischemic shock $(41,42)$. AKT directly regulates the apoptotic machinery by phosphorylating and inactivating proapoptotic proteins such as Bad, which controls mitochondrial release of cytochrome c. AKT also indirectly controls apoptosis through regulation of transcription. Phosphorylation of the Forkhead family of transcription factors by AKT inhibits transcription of pro-apoptotic genes such as FasL.

Because it has been suggested that the EGFR-PI3K-AKT pathway is related to radiosensitivity in BDC, we next investigated whether ZD1839 acts as a radiosensitiser for BDC. ZD1839 (Iressa) is a selective EGFR-tyrosine kinase inhibitor that blocks signal transduction pathways implicated in the proliferation and survival of cancer cells, but does so with little or no activity against other kinases. Although it has been shown that ZD1839 acts as an anti-tumor agent for many cancers, comparable research with BDC has not been reported to date. Therefore, we examined the effects of ZD1839 on the growth of two BDC cell lines. The growth assay demonstrated that ZD1839 significantly inhibits proliferation of both cell lines in a dose-dependent manner (Fig. 1b). The $\mathrm{ED}_{50}$ concentrations of ZD1839 for BDC cells are similar to those observed with other human cancer cells. Moreover, Western blot analysis using phosphospecific antibody revealed that ZD1839 $(1 \mu \mathrm{M})$ inhibited radiation-induced cell surviving signals mediated through EGFR, such as ERK, p38, JNK, and AKT, at a lower 
dose than the $\mathrm{ED}_{50}$ values for both cell lines (Figs. 2 and 4). These results suggest that ZD1839 has an anti-tumor effect in BDC. Recently, it has been reported in several cancers that ZD1839 has the potential to act as a radiosensitiser (2733). Therefore, we investigated the relationship between radiosensitivity and ZD1839. At a concentration of $1 \mu \mathrm{M}$ ZD1839, clonogenic cell survival values were not increased in comparison with control (non-radiation) conditions. In contrast, clonogenic cell survival was decreased with the combination of radiation and the same concentration of ZD1839 (Fig. 5a and b). Clonogenic assays demonstrated that ZD1839 enhances BDC sensitivity to radiation. This is the first report to show that ZD1839 acts as a radiosensitiser for BDC, and these results are consistent with those made from research with other cancers.

It has also been suggested that LY294002 may promote apoptosis of BDC cells by suppressing phosphorylation of AKT-mediated PI3K, with a resulting improvement in radioresistance. In contrast, the mechanisms underlying activity of ZD1839 as a radiosensitiser in BDC were unclear. It is suspected that ZD1839 suppresses activation of downstream signaling pathways, particularly AKT, by blocking autophosphorylation of EGFR. AKT is downstream of PI3K, RAS, PTEN, and EGFR; therefore, oncogenic mutation or deletion of these genes in BDC cells constitutively activates AKT and may result in radioresistance. In our study, ZD1839, considered a selective tyrosine kinase inhibitor for EGFR, increased radiosensitivity not only in EGFR-overexpressing HuCCT-1 cells but also in TFK-1 cells, which have a much lower expression of EGFR. One hypothesis for an effective response independent of EGFR expression is that ZD1839 might directly suppress the PI3K-AKT pathway without mediating RAS by inactivating the erbB-2/erbB-3 heterodimer $(43,44)$. The erbB-3 protein has at least six docking sites and activating sites for PI3K (the regulatory p85 subunit of PI3K) (45). In addition, erbB-2 was found to be overexpressed in TFK-1 cells (Fig. 1a), and our preliminary study suggests that erbB-3 is expressed in both HuCCT-1 and TFK-1 cell lines (Fig. 1a). When the previous and our results are considered together, we suspect that treatment with ZD1839 might dephosphorylate erbB-2 and down-regulate the PI3K-AKT pathway through dephosphorylation of erbB-3.

Furthermore, ZD1839 produced an effective response to radiation despite the different $\mathrm{K}$-ras gene status in the cell lines. It has been recognized that cells with mutated K-ras are more resistant to radiation compared with cells without mutations (wild-type gene sequence). Direct sequencing of the two cell lines using an autosequencer revealed that HuCCT-1 cells have a transversion type of mutation in codon 12 , whereas TFK-1 cells have the wild-type sequence (data not shown). In HuCCT-1 cells, K-ras was constitutively activated, and thus phosphorylation of AKT might not be completely suppressed by ZD1839. This suggests that a ras-independent signal pathway, which moves through EGFR to AKT, may contribute to the observed radioresistance of BDC. Additionally, it has been reported that inactivating mutations or a loss of PTEN expression leads to increased levels of PI3K products in cells, followed by increased cell proliferation and resistance to apoptosis. Therefore, we examined the level of PTEN protein using Western blot analysis: deletion of
PTEN was not detected in either of the cell lines (data not shown). Further studies are needed to understand the mechanisms underlying the ZD1839-induced increase in radiosensitivity of BDC cells.

In conclusion, our study demonstrated that ZD1839 (Iressa) can suppress growth in two BDC cell lines and that AKT activation might play a major role in the clinical radioresistance of BDC. Our findings indicate that ZD1839 might block the EGFR-RAS-PI3K-AKT signal pathway, and thus we conclude that ZD1839 is a candidate for radiosensitisation of BDC in the clinical setting.

\section{Acknowledgements}

The authors extend special thanks to Drs Y. Fujimoto, K. Morinaka and Y. Kuwada for helpful discussions and technical assistance. We wish to thank the Research Center for Molecular Medicine, Hiroshima University School of Medicine, for the use of their facilities.

\section{References}

1. Chen Y, Wang XL, Yan ZP, Cheng JM, Wang JH, Gong GC, Qian S, Luo JJ and Liu QX: HDR- ${ }^{192}$ Ir intraluminal brachytherapy in treatment of malignant obstructive jaundice. World $\mathbf{J}$ Gastroenterol 10: 3506-3510, 2004.

2. Klapper LN, Glathe S, Vaisman N, Hynes NE, Andrews GC, Sela M and Yarden Y: The ErbB-2/HER2 oncoprotein of human carcinoma may function solely as a shared coreceptor for multiple stroma-drived growth factors. Proc Natl Acad Sci USA 96: 4995-5000, 1999.

3. Suzuki M, Umino T, Katayo T, Takeuchi H, Oikawa M, Ono K, Hayashi Y, Satou T and Matsuno M: Biliary metalic stenting and chemoradiation therapy for unresectable bile duct carcinoma. J Biliary Tract Pancreas 22: 255-259, 2001.

4. Wilks AF: Protein tyrosine kinase growth factor receptors and their ligands in development, differentiation, and cancer. Adv Cancer Res 60: 43-73, 1993.

5. Woodburn JR: The epidermal growth factor receptor and its inhibition cancer therapy. Pharmacol Ther 82: 241-250, 1999.

6. Ito Y, Takeda T, Sasaki T, Yamada T, Ishiguro S, Imaoka S, Tsujimoto M, Sakon M, Higashiyama S, Monden M and Matsuura N: Expression and clinical significance of erbB family in intrahepatic cholangiocellular carcinoma. Pathol Res Pract 197: 95-100, 2001.

7. Slamon DJ, Clark GM, Wong SG, Levin WJ, Ullrich A and McGuire WL: Human breast cancer: correlation of relapse and survival with amplification of the HER2/neu oncogene. Science 235: 177-182, 1987

8. Suzuki H, Isaji S, Pairojkul C and Uttaravichien T: Comoparative clinicopathological study of resected intrahepatic cholangiocarcinoma in northeast Thailand and Japan. J Hepatobiliary Pancreat Surg 7: 206-211, 2000.

9. Chow NH, Huang SM, Chan SH, Mo LR, Hwang MH and Su WC: Significance of c-erbB-2 expression in normal and neoplastic epithelium of biliary tract. Anticancer Res 15: 1055-1060, 1995.

10. Endo K, Yoon BI, Pairojkul C, Demetris AJ and Sirica AE: ERBB-2 overexpression and cyclooxygenase-2 up-regulation in human chorangiocarcinoma and risk condition. Hepatology 36 : 439-450, 2002 .

11. Han J, Lee JD, Bibbs L and Ulevitch RJ: A MAP kinase targeted by endotoxin and hyperosmolarity in mammalian cells. Science 265: 808-811, 1994.

12. Lee JC, Laydon JT, McDonnnell PC, Gallagher TF, Kumar S, Green D, McNulty D, Blumenthal MJ, Heys JR and Landvatter SW: A protein kinase involved in the regulation of inflammatory cytokinase biosynthesis. Nature 372: 739-746, 1994.

13. Dent P, Reardon DB, Park JS, Bowers G, Logsdon C, Valerie K and Schmidt-Ullrich R: Radiation-induced release of transformating growth factor alpha activates the epidermal growth factor receptor and mitogen-activated protein kinase pathway in carcinoma cells, leading to increased proliferation and protection from radiation-induced cell death. Mol Biol Cell 10: 2493-2506, 1999. 
14. Hagan M, Wang L, Hanley JR, Park JS and Dent P: Ionizing radiation-induced mitogen-activated protein (MAP) kinase activation in DU145 prostate carcinoma cells: MAP kinase inhibition enhances radiation-induced cell killing and G2/Mphase arrest. Radiat Res 153: 371-383, 2000.

15. Bulavin DV, Amundson SA and Fornace AJ: p38 and Chk1 kinases: different conductors for the $\mathrm{G}(2) / \mathrm{M}$ checkpoint symphony. Curr Opin Genet Dev 12: 92-97, 2002.

16. Gupta AK, Bakanauskas VJ, Cerniglia GJ, Cheng Y, Bernhard EJ, Muschel RJ and McKenna WG: RAS-mediated radiation resistance is not linked to MAP kinase activation in two bladder carcinoma cell lines. Radiat Res 154: 64-72, 2000.

17. Claus B, Paul K, Justine R, Heidrun F, Michael B and Wilfried B: MEK1 and ERK1/2 kinases as targets for the modulation of radiation responses. Anticancer Res 20: 3243-3250, 2000.

18. Grana TM, Rusyn EV, Zhou H, Sartor CI and Cox AD: Ras mediates radiaoresistance through both phosphatidylinositol 3-kinase-dependent and Raf-dependent but mitogen-activated protein kinase/extracellular signal-regulated kinase kinaseindependent signaling pathways. Cancer Res 62: 4142-4150, 2002.

19. Zhou BP, Liao Y, Xia W, Spohn B, Lee MH and Hung MC: Cytoplasmic localization of $\mathrm{p} 21 \mathrm{Cip} 1 / \mathrm{WAF} 1$ by Akt-induced phosphorylation in HER2/neu-overexpressing cells. Nat Cell Biol 3: $245-252,2001$.

20. Rossig L, Jadidi AS, Urbich C, Badorff C, Zeiher AM and Dimmeler S: Akt-dependent phosphorylation of p21Cip1 regulates PCNA binding and proliferation of endothelial cells. Mol Cell Biol 21: 5644-5657, 2001.

21. Kim D, Kim S, Koh H, Yoon SO, Chung AS, Cho KS and Chung J: Akt/PKB promotes cancer cell invasion via increased motility and metalloprotease production. FASEB J 15: 1953-1962, 2001.

22. Gupta AK, Bakanauskas VJ, Cerniglia GC, Cheng Y, Bernhard EJ, Muschel RJ and McKenna WG: The Ras radiation resistance pathway. Cancer Res 61: 4278-4282, 2001.

23. Gupta AK, Cerniglia GJ, Mick R, Ahmed MS, Bakanauskas VJ, Muschel RJ and McKenna WG: Radiation sensitization of human cancer cells in vivo by inhibiting the activity of PI3K using LY294002. Int J Radiat Oncol Biol Phys 56: 846-853, 2003.

24. Edwards E, Geng L, Tan J, Onishko H, Donnelly E and Hallahan DE: Phosphatidylinositol 3-kinase/Akt signaling in the response of vascular endothelium to ionizing radiation. Cancer Res 62: 4671-4677, 2002.

25. Tanno S, Yanagawa N, Habiro A, Koizumi K, Nakano Y, Osanai M, Mizukami Y, Okumura T, Testa JR and Kohgo Y: Serine/threonine kinase AKT is frequently activated in human bile duct cancer and is association with increased radioresistance. Cancer Res 64: 3486-3490, 2004.

26. Moasser MM, Basso A, Averbunch SD and Rosen N: The tyrosine kinase inhibitor ZD1839 ('Iressa') inhibits HER2-driven signaling and suppresses the growth of HER2-overexpressing tumor cells. Cancer Res 61: 7184-7188, 2001.

27. Maddineni SB, Sangar VK, Hendry JH, Margison GP and Clake NW: Differential radiosensitisation by ZD1839 (Iressa), a highly selective epidermal growth factor receptor tyrosine kinase inhibitor in two related bladder cancer cell lines. Br J Cancer 92: 125-130, 2005.

28. Gupta AK, McKenna WG, Weber CN, Feldman MD, Goldmith JD, Mick R, Machtay M, Rosenthal DI, Bakanauskas VJ, Cerniglia GJ, Bernhard EJ, Weber RS and Muschel RJ: Local recurrence in head and neck cancer: relationship to radiation resistance and signal transduction. Clin Cancer Res 8: 885-892, 2002.
29. Stea B, Falsey R, Kislin K, Patel J, Glanzberg H, Carey S, Ambrad AA, Meuillet EJ and Martinez JD: Time and dosedependent radiosensitization of the glioblastoma multiple U251 cells by the EGF receptor tyrosine kinase inhibitor ZD1839 ('Iressa'). Cancer Lett 202: 43-51, 2003.

30. Williams KJ, Telfer BA, Stratford IJ and Wedge SR: ZD1839 ('Iressa'), a specific oral epidermal growth factor receptor-tyrosine kinase inhibitor, potentiates radiotherapy in a human colorectal cancer xenograft model. Br J Cancer 86: 1157-1161, 2002.

31. Huang SM, Li J, Armstrong EA and Harari PM: Modulation of radiation response and tumor-induced angiogenesis after epidermal growth factor receptor inhibition by ZD1839 (Iressa). Cancer Res 62: 4300-4306, 2002.

32. Solomon B, Hagekyriakou J, Trivett MK, Stacker SA, McArthur GA and Cullinane C: EGFR blockade with ZD1839 ('Iressa') potentiates the antitumor effects of single and multiple fractions of ionizing radiation in human A431 squamous cell carcinoma. Int J Oncol Biol Phys 55: 713-723, 2003.

33. Gee JM and Nicholson RI: Expanding the therapeutic repertoire of epidermal growth factor receptor blockade: radiosensitization. Breast Cancer Res 5: 126-129, 2003.

34. Liang K, Jin W, Knuefermann C, Schmidt M, Mills GB, Ang KK, Milas L and Fan Z: Targeting the phosphatidylinositol 3-kinase/ Akt pathway for enhancing breast cancer cells to radiotherapy. Mol Cancer Ther 2: 353-360, 2003.

35. Akimoto T, Hunter NR, Buchmiller L, Mason K, Ang KK and Milas L: Inverse relationship between epidermal growth factor receptor expression and radiocurability of murine carcinomas. Clin Cancer Res 5: 2884-2890, 1999.

36. Hosoi Y: Radiation-induced signal transduction pathways: DNA double-strand break repair and radiation-induced activation of EGFR. Jpn J Cancer Clin 50: 1055-1060, 2004.

37. Alessi DR, Andjelkovic M, Caudwell B, Cron P, Morrice N, Cohen $\mathrm{P}$ and Hemmings BA: Mechanism of activation of protein kinase B by insulin and IGF-1. EMBO J 15: 6541-6551, 1996.

38. Alessi DR, Deak M, Casamayor A, Caudwell FB, Morrice N, Norman DG, Gaffney P, Reese CB, MacDougall CN, Harbison D, Ashworth A and Bownes M: 3-Phosphoinositide-dependent protein kinase-1 (PDK1): structural and functional homology with the Drosophila DSTPK61 kinase. Curr Biol 7: 776-789, 1997.

39. Cantley LC and Neel BG: New insights into tumor suppression: PTEN suppresses tumor formation by restraining the phosphoinositide 3-kinase/AKT pathway. Proc Natl Acad Sci USA 96: 4240-4245, 1999

40. Testa JR and Bellacosa A: AKT plays a central role in tumorigenesis. Proc Natl Acad Sci USA 98: 10983-10985, 2001.

41. Franke TF, Kaplan DR and Cantley LC: PI3K: downstream AKTion blocks apoptosis. Cell 88: 435-437, 1997.

42. Downward J: Mechanisms and consequences of activation of protein kinase B/Akt. Curr Opin Cell Biol 10: 262-267, 1998.

43. Moulder SL, Yakes FM, Muthuswamy SK, Bianco R, Simpson JF and Arteaga CL: Epidermal growth factor receptor (HER1) tyrosine kinase inhibitor ZD1839 (Iressa) inhibits HER2/neu (erbB2)-overexpressing breast cancer cells in vitro and in vivo. Cancer Res 61: 8887-8895, 2001.

44. Anido J, Matar P, Albanell J, Guzman M, Rojo F, Arrbas J, Averbuch S and Baselga J: ZD1839, a specific epidermal growth factor receptor (EGFR) tyrosine kinase inhibitor, induces the formation of inactive EGFR/HER2 and EGFR/HER3 heterodimers and prevents heregulin signaling in HER2-overexpressing breast cancer cells. Clin Cancer Res 9: 1274-1283, 2003.

45. Olayioye MA, Neve RM, Lane HA and Hynes NE: The ErbB signaling network: receptor heterodimerization in development and cancer. EMBO J 19: 3159-3167, 2000. 